\title{
Biodiesel production from the black soldier fly larvae grown on food waste and its fuel property characterization as a potential transportation fuel
}

\author{
Jo-Yong Park ${ }^{1^{*}}$, Sungyup Jung ${ }^{{ }^{*}}$, Yong-Gyu Na ${ }^{1}$, Cheol-Hwan Jeon ${ }^{1}$, Hwa-Yeon Cheon ${ }^{1}$, \\ Eun-Young Yun ${ }^{3}$, Sang-hoon Lee ${ }^{4}$, Eilhann E. Kwon ${ }^{2^{\dagger}}$, Jae-Kon $\mathrm{Kim}^{1^{+}}$ \\ ${ }^{1}$ Research Institute of Petroleum Technology, Korea Petroleum Quality \& Distribution Authority, Cheongju 28115, Republic of Korea \\ ${ }^{2}$ Department of Environment and Energy, Sejong University, Seoul 05006, Republic of Korea \\ ${ }^{3}$ Department of Integrative Biological Sciences and Industry, Sejong University, Seoul 05006, Republic of Korea \\ ${ }^{4}$ GreenTeko,Inc., Gyeonggi-do 15655, Republic of Korea \\ *These authors contributed equally to this work.
}

\begin{abstract}
Insects have a great potential to be used as feedstocks for biodiesel production due to their intrinsic high lipid contents. In particular, biodiesel production from black soldier fly larvae (BSFL) is promising because of its advantages in engineering aspects such as a rapid proliferation, more lipid storage due to long-development time in larva stage, self-separation from organic waste. In this study, biodiesel was synthesized through (trans)esterification of BSFL grown on food waste to achieve both biofuel production from organic waste materials. In addition, all fuel properties of the biodiesel were examined to evaluate its feasibility as a potential transportation fuel in Korea. The highest yield of biodiesel obtained in this study was 86.51\%. All the parameters of biodiesel produced from BSFL satisfied the Korea fuel standard (KS M 2965) except oxidation stability. The quality criterion of oxidation stability met the fuel standard with an addition of small quantity of tert-butylhydroquinone.
\end{abstract}

Keywords: Biodiesel, Black soldier fly larvae, Fatty acid methyl esters, Fatty acids, Fuel properties, Quality standards

\section{Introduction}

Substantial quantity of food waste is generated in the world, and the sources of food waste generation include household, restaurants, agricultural and food industries [1]. The European Union (EU) reported that the annual production of food waste from 28 countries in the EU has continuously increased, and the estimation of food waste production in 2020 is 116 million tons [2]. In Korea, the annual production of food waste was approximately 5 million tons [3]. Currently, the food waste is being disposed composting or landfill methods. Composting is a broadly used and well-established way to valorize food waste for its recycling as ingredients in the agricultural industry. However, composting process requires continuous and proper managements for carbon to nitrogen ratio, moderate temperature (50 to $70^{\circ} \mathrm{C}$ ), and aerobic conditions with long reaction time to convert food waste into desired composts [4] Landfill methods produce biogas, composed of $\mathrm{CO}_{2}$ and $\mathrm{CH}_{4}$ from biological reactions in the oxygen-limited conditions. It releases leachate and greenhouse gases, and the completion of the anaerobic reactions takes a few months [5]. In addition, the installation of landfill plant requires high capital costs and large spaces [6]. Thus, it is beneficial to find an innovative and environmentally benign way to dispose and valorize the food waste.

Insects store energy in the form of triglycerides (lipids) and glycogen in their main body cell [7]. Given that the food waste is a feed for insects, a variety of chemical constituents of food waste can be transformed into lipids in the fat body cell of insects by their metabolisms [8, 9]. Lipids are important feedstocks for biodiesel production through a well-established industrially used chemical reaction, called transesterification. Soybeans and palms
This is an Open Access article distributed under the terms of the Creative Commons Attribution Non-Commercial License (http://creativecommons.org/licenses/by-nc/3.0/) which permits unrestricted non-commercial use, distribution, and reproduction in any medium, provided the original work is properly cited.

Copyright (C) 2022 Korean Society of Environmental Engineers
Received December 28, 2020 Accepted March 23, 2021

${ }^{\dagger}$ Corresponding author

E-mail: ekwon74@sejong.ac.kr; jkkim@kpetro.or.kr

Tel: +82-2-3408-4166; +82-43-240-7931 Fax: +82-2-3408-4320

ORCID: 0000-0001-7438-7920 (E.E.K); 0000-0002-3458-8661 (J.K.K) 
have been broadly used as feedstocks for biodiesel synthesis, and their lipid contents are 18 and $36 \%$, respectively [10]. It is known that insects also have competitive or higher lipid contents (30 $-40 \%$ ) in reference to the oil-bearing crops [9, 11]. In addition, the high proliferation rate of insects can accelerate the conversion of food waste into lipid. In Table 1, lipid contents of different oil-bearing biomass feedstocks and the estimation of biodiesel productivity are summarized. Thus, the high biodiesel productivity from insects that grew up on food waste is expected, and these can achieve two goals: (a) disposal of food waste and (2) production of energy as a form of biodiesel through an environmentally friendly process.

Black soldier fly, referring to Hermetia illucens (H. illucens), is a widespread fly of the family Stratiomyidae and lives in tropical and temperature regions. Black solider fly larvae (BSFL) have three weeks of development time, which is much longer than the development time of house flies $(<5 \mathrm{~d})$. It means that a single larva of black solider fly can consume more food waste and produce larger pupae in reference to house flies [11, 12]. The lipid contents of BSFL and their pupae vary in the range of 11 and $42 \%$, and the average value is $29 \%$ (dry basis) [11]. Because of the high protein contents of BSFL ( $\geq 32 \%$, dry basis), the remaining debris of BSFL after lipid extraction can be used as a feed for animals [11]. Prior to entering the pupa stage, BSFL instinctively leave the substrate to move to a high and clean place [13], meaning no need of additional separation step for BSFL from food waste. Such instinctive behavior, also called self-harvesting, can help to remove a labor-intensive collection process.

Because of the aforementioned advantages, BSFL have received considerable attentions to be used as a feedstock for biodiesel production. In general, previous studies examined the yields of biodiesel using BSFL or lipids extracted from BSFL depending on the various reaction conditions [11]. They also reported chemical and physical properties of BSFL-derived biodiesel such as density, moisture content, composition of fatty acid methyl esters (FAMEs: biodiesel contents), acid value, viscosity, and phosphorous content. Also, the heating value and cetane number of FAMEs derived from BSFL were competitive with other biodiesels [10, 14-20].

However, the previous studies did not fully prove the quality criteria of biodiesel to be used as a transport fuel, and no study has reported all the parameters of quality specification for biodiesel as a liquid transportation fuel. Although lipid contents of BSFL are highly contingent on the feeds of BSFL, the BSFL grown on food waste were also rarely adapted for biodiesel production.

In this study, biodiesel was synthesized using lipids extracted from BSFL grown on organic food waste, and all the fuel properties are evaluated to decide the fuel feasibility of the BSFL-derived biodiesel. The relationship between biodiesel yield and reaction conditions (lipid to methanol ratio, catalyst loading, reaction temperature and time) was also examined to improve the reaction efficiency for biodiesel production. After biodiesel production, all the quality requirements of the Korea biodiesel fuel standards (KS M 2965) were evaluated using the biodiesel produced from BSFL lipid. Lastly, the fuel characteristics of BSFL-derived biodiesel were compared with other biodiesel fuels.

\section{Materials and Methods}

\subsection{Lipid Extraction from BSFL}

BSFL were grown up, feeding food waste for $14 \mathrm{~d}$ by Greenteko Co., Ltd. Approximately 25,000 larvae were grown per $1 \mathrm{~m}^{2}$, and the weight of the BSFL grown was about $5 \mathrm{~kg}$ per $\mathrm{m}^{2}$. The collected BSFL were then dried at $60^{\circ} \mathrm{C}$ in a conveyor oven (Tae Yang Tech instrument company, Korea). Lipid was extracted from the dried BSFL with a hexane using a previously reported liquid-liquid extraction method [16]. The extracted lipid was centrifuged at $600 \mathrm{rpm}$ for $10 \mathrm{~min}$ to separate lipid from the residual solids and decompressed hexane. Protein, lipid, carbohydrate, ash, and moisture contents were analyzed by the analysis methods provided from the Association of Official Analytical Chemists (AOAC 1990). The crude protein and lipid contents were analyzed using nitrogen determination and acid hydrolysis methods [21, 22].

\subsection{Biodiesel Synthesis and Purification}

$5 \mathrm{~g}$ of extracted BSFL lipid was used to synthesize biodiesel through (trans)esterification. Different experimental conditions (lipid to methanol ratio, catalyst loading, reaction temperature, and reaction time) were used for biodiesel production. Lipid to methanol ratio was in the range of $1: 4$ to $1: 10$, and the amount of acid catalyst $\left(\mathrm{H}_{2} \mathrm{SO}_{4}\right)$ loading was changed from 2 to $6 \%$, relative to lipid. The reaction temperature was between 50 and $80^{\circ} \mathrm{C}$, and the reaction times were $2,4,6$, and $8 \mathrm{~h}$. The resulting products were cooled down to $25^{\circ} \mathrm{C}$, and methanol was separated through distillation

Table 1. Lipid Content in Oil-bearing Biomass Feedstocks and Estimation of Their Biodiesel Productivity [10, 11]

\begin{tabular}{|c|c|c|c|}
\hline Feedstocks & $\begin{array}{c}\text { Oil (lipid) contents } \\
\text { (\% oil by wt. in dry biomass) }\end{array}$ & $\begin{array}{c}\text { Oil yield } \\
\left.\text { (L oil ha-1 } \text { year }^{-1}\right)\end{array}$ & $\begin{array}{l}\text { Biodiesel productivity } \\
\left(\mathrm{kg}^{\text {biodiesel ha }} \text { hear }^{-1}\right)\end{array}$ \\
\hline Soybean & 18 & 636 & 562 \\
\hline Rapeseed & 41 & 974 & 862 \\
\hline Palm & 36 & 5,366 & 4,747 \\
\hline Jatropha & 28 & 741 & 656 \\
\hline Microalgae & 50 & 97,800 & 86,515 \\
\hline BSFL & $30-40$ & 162,000 & $145,800 \mathrm{a}$ \\
\hline
\end{tabular}

\footnotetext{
${ }^{\text {a }}$ Based on $40 \%$ lipid in BSFL
} 


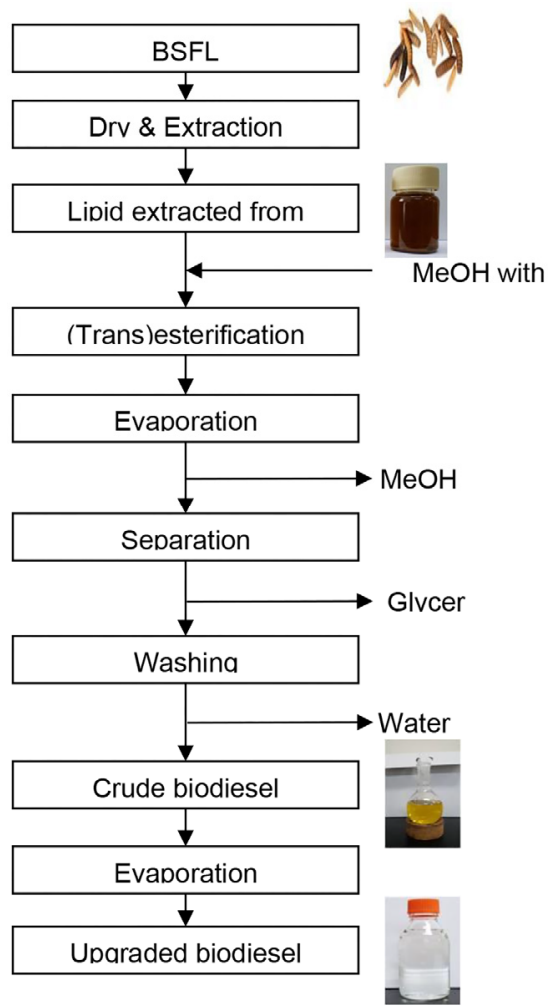

Fig. 1. Experimental procedures for biodiesel synthesis and purification.

process. Glycerol in the lower layer of biodiesel product solutions was removed through layer separation and decantation. The crude biodiesel was washed with distilled water, and then its weight was measured gravimetrically. Total FAME contents were analyzed with chromatography methods to measure biodiesel yield according to EN 14103. For the purification of BSFL-derived biodiesel, a decompression distillation was conducted. The quality parameters specified in Korea biodiesel fuel standards (KS M 2965) were then measured. The overall experimental procedures are drawn in Fig. 1. Experiments were performed in triplicate, and the errors of all the results were less than $2 \%$.

\subsection{Calculations}

The yield of biodiesel synthesized from BSFL was calculated as the amount of FAME produced against the amount of lipids used as reactant. The yield of the synthesized biodiesel was measured using the crude biodiesel obtained after synthesis was completed. The FAME content was analyzed using EN14103 and calculated using Eq. (1), (2), and (3).

$$
\begin{gathered}
\text { Crude biodiesel }(\%)=\frac{W_{A}}{W_{B}} \times 100 \\
\text { FAME content }(\%)=\frac{\sum A-A_{E I}}{A_{E I}} \times \frac{W_{E I}}{W} \times 100 \\
\text { Biodiesel yield }(\%)=\frac{\text { Crude biodiesel } \times \text { FAME content }}{100}
\end{gathered}
$$

Where,

$\mathrm{W}_{\mathrm{B}}$ is the weight of lipid before reaction (mg),

$\mathrm{W}_{\mathrm{A}}$ is the weight of crude biodiesel after reaction (mg),

$\Sigma \mathrm{A}$ is the sum of FAME area from $\mathrm{C}_{6: 0}-\mathrm{C}_{24: 1}$,

$\mathrm{A}_{\mathrm{EI}}$ is the peak area of methyl nonadecanoate,

$\mathrm{W}_{\mathrm{EI}}$ is the weight of methyl nonadecanoate as internal standard (mg), and

$\mathrm{W}$ is the weight of crude biodiesel (mg).

\subsection{Analysis of Biodiesel Characteristics}

The FAME content in biodiesel was determined following the EN 14103, using gas chromatography (GC) (Agilent, Palo Alto, USA) equipped with a flame ionization detector (FID) and a chromatography data management system. The fused silica capillary column (SP-2380 model, Supelco, Inc., USA) used in the GC analyzer was $30 \mathrm{~m}$ in length and $0.25 \mathrm{~mm}$ in inside diameter, with a film thickness of $0.2 \mu \mathrm{m}$. Methyl nonadecanoate was used as an internal standard solution. The cold filter plugging point (CFPP) measurement was carried out following KS M 2411 on the model FPP5Gs (ISL, Verson, Carpiquet, France). About $45 \mathrm{~mL}$ of sample was cooled under the specified conditions. At $1^{\circ} \mathrm{C}$ of interval, a $200 \mathrm{~mm} \mathrm{H}_{2} \mathrm{O}$ vacuum was applied to draw up the sample into a pipette through a filter. As the sample was cooled, the amount of crystals increased. The temperature at which either the sample ceased to flow through the filter within $60 \mathrm{~s}$ or failed to return into the test jar was recorded as the CFPP. The cloud point (CP) was measured by a Mini Pour/Cloud Point Tester MPC-602 (Tanaka, Japan) covering a temperature range from -60 to $51^{\circ} \mathrm{C}$. This tester was in accordance with ASTM D2500 and ASTM D637.

The oxidation stability measurements were carried out following European standard EN 14112 with the model 743 Rancimat (Metrohm, Herisau, Switzerland). About $3 \mathrm{~g}$ of samples were analyzed under constant air flow of $10 \mathrm{~L} / \mathrm{h}$ at $110^{\circ} \mathrm{C}$ heating block temperature. The temperature correction $(\Delta T)$ was set to $1.5^{\circ} \mathrm{C}$. The KS M ISO 6245 method using a Brinkman Metrohm 809 Titrando instrument (Riverview, FL) was utilized to measure acid value (AV). The kinematic viscosity was determined according to KS M 2014 by measuring the time for a volume of liquid to flow under gravity through a calibrated capillary viscometer at $40^{\circ} \mathrm{C}$. The test method was done using Automated Kinematic Viscometer CAV-2100F (Cannon instrument company, USA).

\section{Results and Discussion}

\subsection{Characteristics of BSFL Lipid}

FAMEs, biodiesel components, were produced from the conversion of lipids, in particular, transesterification of triglycerides and esterification of free fatty acids. Because the (trans)esterification reactions are susceptible to the presence of organic and inorganic impurities that can be presented in biomass feedstocks [23], lipid content was extracted from BSFL prior its conversion to biodiesel. The lipid was extracted using liquid/liquid extraction method. In Table 2, major chemical constituents of lipid extracted from BSFL and left-over cake (pressed cake) are shown. Lipid extracted had $85.49 \%$ of purity having $9.91 \%$ protein, $2.65 \%$ 
Table 2. Chemical Constituents of Lipid Extracted from BSFL and Left-over Cake

\begin{tabular}{lcc}
\hline Chemical constituents & Lipid extracted (\%) & Left-over cake (\%) \\
\hline Water & 0.58 & 1.13 \\
Carbohydrate & 2.65 & 19.67 \\
Protein & 9.91 & 64.20 \\
Fat (lipid) & 85.49 & 8.24 \\
Ash & 1.37 & 6.76 \\
\hline
\end{tabular}

carbohydrate, $1.37 \%$ ash, and $0.58 \%$ of water. The major compounds of left-over BSFL cake after lipid/lipid extraction were protein $(64.20 \%)$, followed by carbohydrate (19.67\%), lipid (8.24\%), ash (6.76\%), and water (1.13\%). From the lipid extraction process, high lipid content, a feedstock for biodiesel production, was obtained. Also, other nutrients (protein and carbohydrate) abundant cake, which can be used as a feed for animals, were prepared.

To further understand the presence of other contents in the lipid extracted, iodine and acid values were examined (Table 3). Note that the iodine value is associated with unsaturated fatty acids contained in the lipid. The iodine value of BSFL (73.4 g Iodine $100 \mathrm{~g}^{-1}$ lipid) was lower than that of soybean oil (117 143 g Iodine $100 \mathrm{~g}^{-1}$ lipid) and waste cooking oil (108.4 g Iodine $100 \mathrm{~g}^{-1}$ lipid), but higher than that of palm oil (48 - $58 \mathrm{~g}$ Iodine $100 \mathrm{~g}^{-1}$ lipid) [10, 24, 25] . This demonstrates that lipid extracted from BSFL has a lower fraction of unsaturated fatty acids than soy and waste cooking oils. The unsaturated fatty acids can suffer from chemical bond scissions, resulting in undesired side products such as volatile fatty acids and alkanes. The side products increase the impurity in the final product, otherwise requiring additional separation processes. Therefore, the low quantity of unsaturated fatty acids in lipid extracted from BSFL is beneficial in terms of its fuel quality.

Acid value (AV) is a parameter that indicates the amount of free fatty acid and other acids (e.g., residual catalyst) contained in the samples. AV of lipid extracted from BSFL (1.65 mg KOH $\mathrm{g}^{-1}$ lipid) was placed in the middle of the AV ranges of other feedstocks for biodiesel production as shown in Table 3. Considering relatively lower iodine value and moderate AV of BSFL, it is inferred that BSFL can be considered a competitive lipid source for biodiesel production.

\subsection{Biodiesel Synthesis and Purification}

For biodiesel production from the BSFL-derived lipid, (trans) ester- ification was performed with a broadly used acid catalyst (i.e., $\mathrm{H}_{2} \mathrm{SO}_{4}$ ). The acid catalyst was chosen because alkaline catalysts can lead to formations of soap and alcohol through the saponification reaction of free fatty acids (acid value $>1$ ). To obtain high yield of biodiesel production, different reaction conditions (lipid to methanol ratio, catalyst loading, reaction temperature and time) were used for (trans)esterification of BSFL-derived lipid. The results are depicted in Fig. 2.

The relationship between biodiesel yield and lipid to methanol ratio $\left(1: 4,1: 6,1: 8\right.$, and 1:10) was monitored at $70^{\circ} \mathrm{C}$ for $6 \mathrm{~h}$ with $5 \%$ ( $0.25 \mathrm{~g}$ ) of $\mathrm{H}_{2} \mathrm{SO}_{4}$ catalyst. The highest yield (86.51\%) of biodiesel was shown at 1:8 ratio (Fig. 2(a)). When the methanol ratio was lower, the biodiesel yields significantly decreased, and the higher methanol loading did not improve biodiesel yield. To further expedite (trans)esterification reactions for higher yields of biodiesel, more catalyst loading, higher temperature, and longer reaction time were used. However, no remarkable improvement of biodiesel yield was shown. In contrast, the significant decrease of biodiesel yield was shown when the lower methanol or catalyst loadings, reaction temperature, and shorter period of reaction time were used.

Table 4 shows the chemical compositions of FAMEs in biodiesel. BSFL-derived biodiesel was composed of 12 types of FAMEs, and major constituents of FAMEs were methyl laureate $\left(\mathrm{C}_{12: 0}\right.$, $23.6 \%)$, methyl oleate $\left(\mathrm{C}_{18: 1}, 23.2 \%\right)$, methyl palmitate $\left(\mathrm{C}_{16: 0}\right.$, $20.3 \%$ ), and methyl linoleate $\left(\mathrm{C}_{18: 2}, 15.9 \%\right) .55 .9 \%$ of biodiesel were saturated FAMEs, while monosaturated and polyunsaturated FAMEs were $26.0 \%$ and $18.1 \%$, respectively. BSFL-derived biodiesel had relatively higher portion of saturated FAMES, comparing to other biodiesels. These results have good agreement with iodine values as described in Table 3. Other biodiesels derived from edible oils were composed of $\mathrm{C}_{16}$ and $\mathrm{C}_{18}$ FAMEs (Table 4), while BSFL-derived biodiesel showed high quantity of $\mathrm{C}_{12}$ FAME (methyl laureate).

\subsection{Characteristics of Biodiesel Fuel}

To evaluate the feasibility of BSFL-derived biodiesel as a transportation fuel, its properties were further examined. As discussed earlier, the AV of biodiesel is an important parameter to evaluate whether biodiesel will be degraded and cause damages to the internal combustion engines. Also, the measurement of sulfur content in biodiesel should be investigated because sulfur can be oxidized into sulfuric oxides during combustion process of engines. Sulfuric oxides are harmful chemicals and highly regulated by governments. AV (1.04 mg KOH g fuel) and sulfur content (146 mg sulfur $\mathrm{kg}^{-1}$ fuel)

Table 3. Iodine Value and Acid Value of Lipid Extracted from BSFL and Other Bio-oils

\begin{tabular}{|c|c|c|c|}
\hline Lipid or oil extracted & Iodine value (g Iodine $100 \mathrm{~g}^{-1}$ lipid) & Acid value (mg $\mathrm{KOH} \mathrm{g}^{-1}$ lipid) & Refs. \\
\hline BSFL & 73.4 & 1.65 & this study \\
\hline Soybean & $128-143$ & $0.1-0.2$ & \\
\hline Palm & $48-58$ & $6.9-50.8$ & \\
\hline Waste cooking oil & 108.4 & 0.15 & {$[10,24,25]$} \\
\hline Rapeseed & $94-120$ & 0.2 & \\
\hline Jatropha & $82-98$ & $15.6-43$ & \\
\hline
\end{tabular}



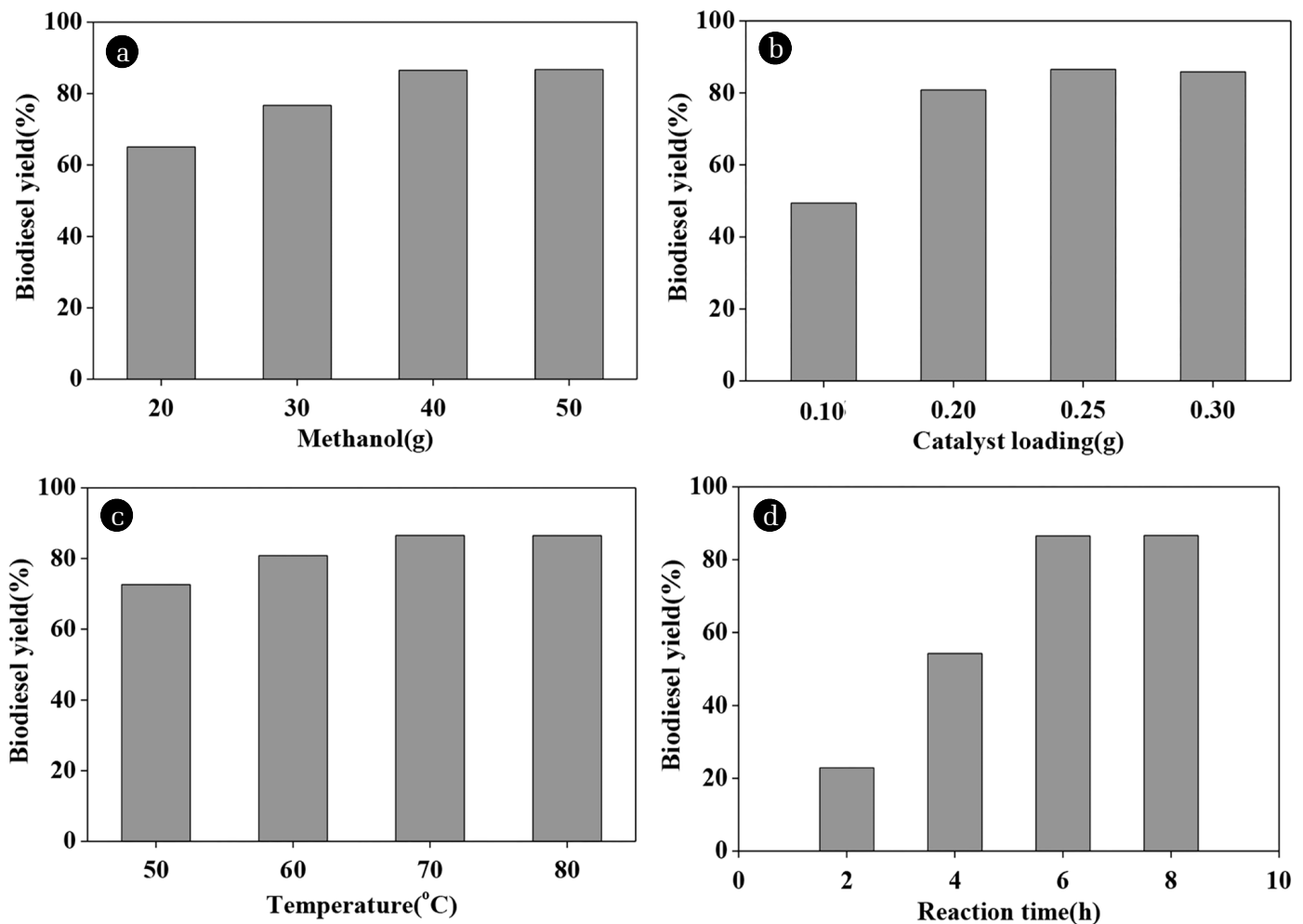

Fig. 2. Biodiesel synthesis from transesterification of BSFL under various reaction conditions. Reaction conditions for transesterification of BSFL were $5 \mathrm{~g}$ of lipid, $40 \mathrm{~g}$ methanol, $0.25 \mathrm{~g}$ catalyst loading, $70^{\circ} \mathrm{C}$ and $6 \mathrm{~h}$ reaction time. Other parameters were changed to study effects of (a) methanol ratio (20 to $50 \mathrm{~g})$, (b) catalyst loading $(0.10$ to $0.30 \mathrm{~g})$, (c) reaction temperature (50 to $\left.80^{\circ} \mathrm{C}\right)$, and (d) reaction time $(2$ to $8 \mathrm{~h}$ ).

Table 4. The FAME Compositions in BSFL Biodiesel and Biodiesel Derived from Other Biomass Feedstocks

\begin{tabular}{|c|c|c|c|c|c|c|}
\hline FAMEs & $\begin{array}{l}\text { BSFL (\%) } \\
\text { this study }\end{array}$ & $\begin{array}{c}\text { Soybean (\%) } \\
{[10]}\end{array}$ & $\begin{array}{c}\text { Palm (\%) } \\
{[10]}\end{array}$ & $\begin{array}{c}\text { Waste cooking oil (\%) } \\
\text { [25] }\end{array}$ & $\begin{array}{c}\text { Rapeseed (\%) } \\
\text { [28] }\end{array}$ & $\begin{array}{c}\text { Jatropha (\%) } \\
\text { [28] }\end{array}$ \\
\hline C8:0 & - & - & 0.8 & - & - & - \\
\hline C10:0 & 0.7 & - & 0.5 & - & - & - \\
\hline C12:0 & 23.6 & 0.1 & 0.3 & - & - & - \\
\hline C14:0 & 6 & 0.1 & 1.1 & 0.1 & 0.1 & 0.1 \\
\hline C14:1 & 0.1 & - & - & - & - & - \\
\hline C16:0 & 20.3 & 11.6 & 42.5 & 8.2 & 5.6 & 13.7 \\
\hline C16:1 & 2.7 & 0.2 & 0.2 & 5.2 & 0.3 & 0.9 \\
\hline $\mathrm{C} 17: 0$ & 0.5 & - & - & - & - & - \\
\hline C18:0 & 4.6 & 3.9 & 4.2 & 2.1 & 1.9 & 6.8 \\
\hline C18:1 & 23.2 & 23.7 & 41.3 & 59.7 & 55.1 & 44.3 \\
\hline C18:2 & 15.9 & 53.8 & 9.5 & 19.3 & 26.2 & 33.5 \\
\hline C18:3 & 2.2 & 5.9 & 0.3 & 6.8 & 6.8 & 0.2 \\
\hline C19:0 & - & - & - & - & - & - \\
\hline C20:0 & 0.2 & 0.3 & - & - & 0.6 & 0.2 \\
\hline C20:1 & - & 0.3 & - & - & 1.0 & 0.1 \\
\hline $\mathrm{C} 22: 0$ & - & 0.3 & 0.1 & - & 0.3 & - \\
\hline $\mathrm{C} 22: 1$ & - & 0.1 & - & - & - & - \\
\hline Saturated fatty FAMEs & 55.9 & 16.3 & 49.5 & 10.4 & 8.5 & 20.8 \\
\hline Monounsaturated FAMEs & 26.0 & 24.0 & 41.5 & 64.9 & 55.4 & 45.2 \\
\hline Polyunsaturated FAMEs & 18.1 & 60.0 & 9.8 & 26.1 & 34.0 & 33.8 \\
\hline
\end{tabular}




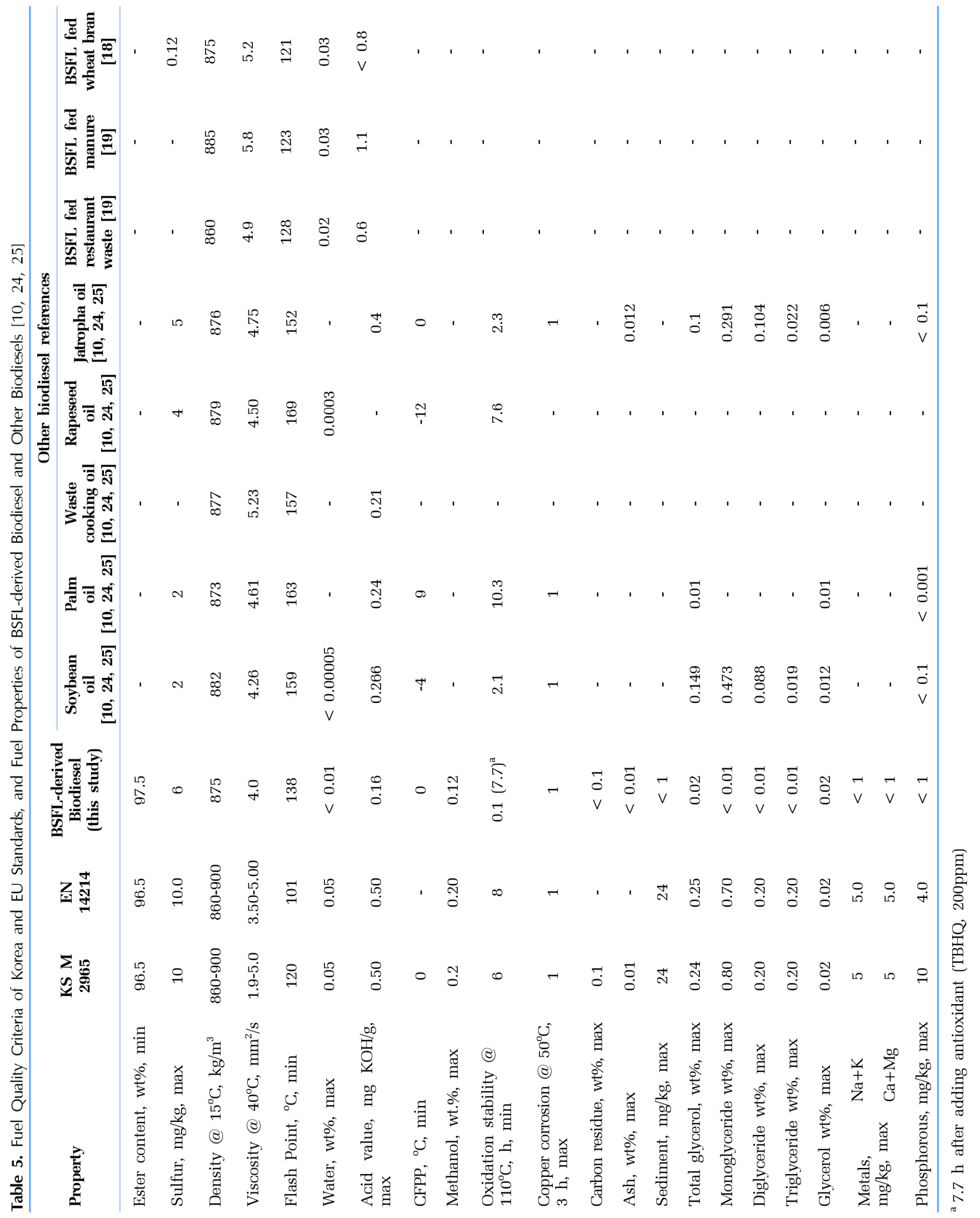


Table 6. Cold Flow Properties of BSFL Derived Biodiesel in Comparison with Other Biodiesels

\begin{tabular}{lcccc}
\hline Biodiesel feedstocks & Cold point $\left({ }^{\circ} \mathbf{C}\right)$ & Pour point $\left({ }^{\circ} \mathbf{C}\right)$ & Cold filter plugging point $\left({ }^{\circ} \mathbf{C}\right)$ & Ref. \\
\hline BSFL & 2 & -1 & -4 & this study \\
Soybean & 0 & -4 & 9 & - \\
Palm & 14 & 13 & -12 & {$[10]$} \\
Waste cooking oil & 3 & 0 & - & \\
Rapeseed & -3 & -10 & 0 & \\
jatropha & 5 & &
\end{tabular}

of the BSFL-derived biodiesel were higher than Korea (KS M 2965) and EU (EN 14214) standards: AV (< $0.50 \mathrm{mg} \mathrm{KOH} \mathrm{g}^{-1}$ fuel) and sulfur (10.0 mg sulfur $\mathrm{kg}^{-1}$ fuel). Thus, it is necessary to have further purification processes to upgrade BSFL-derived biodiesel.

In other previous reports of biodiesel production from insects, $\mathrm{AV}$ and sulfur content of produced biodiesel also did not meet the standards. According to Li et al. [16] the AV (1.1 mg KOH $\mathrm{g}^{-1}$ ) of biodiesel produced from BSFL was higher than EU standard. Nguyen et al. [18] produced biodiesel from BSFL, and they found that the sulfur content in the biodiesel was $1,200 \mathrm{mg} \mathrm{kg}^{-1}$, which was much higher than the quality standards of various countries. The high AV and sulfur contents can be attributed to the presence of unreacted/degraded free fatty acids, sulfuric acid catalyst, or/and intrinsic sulfur content in BSFL lipid. Therefore, the separation of them from biodiesel should be performed to meet the fuel standards in Korea and EU.

The lipid extracted from BSFL had a high sulfur content (430 mg kg-1 lipid), and it decreased to $146 \mathrm{mg} \mathrm{kg}^{-1}$ after evaporation and washing steps. In addition, the AV of the lipid dropped from 1.65 to $1.04 \mathrm{mg} \mathrm{KOH} \mathrm{g}^{-1}$ after both processes. Thus, it was hypothesized that remaining free fatty acids and intrinsic sulfur in lipid were presented in the crude biodiesel.

To obtain high purity biodiesel, decompression distillation was further conducted to obtain evaporated FAMEs fractionally at lower boiling points. Through the fractional distillation approximately $90 \%$ of FAMEs (purified biodiesel) was collected from the crude biodiesel. The sulfur content in the purified biodiesel was reduced to $5.6 \mathrm{mg} \mathrm{kg}^{-1}$ biodiesel, and the AV was $0.16 \mathrm{mg}$

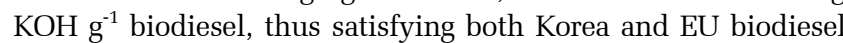
standards.

When the acid and sulfur contents were derived from sulfuric acid, decompression distillation could not work because the boiling point of sulfuric acid is placed between that of $\mathrm{C}_{14}$ and $\mathrm{C}_{16}$ methyl esters. Thus, the sulfur content was likely derived from protein contained in BSFL-derived lipid (Table 2). Note that some types of protein such as methionine and cysteine contain sulfur containing amino acids.

A variety of chemical and physical properties of purified BSFL-derived biodiesel are compared with Korea and EU fuel standards, and those of other biodiesels in Table 5. All the properties met the quality criteria of both Korea and EU biodiesel fuel standards except oxidation stability. This proved that the BSFL-derived biodiesel can be considered a promising biodiesel with some stabilization process. Oxidation stability of biodiesel is an indicator to decide the long-term storage stability of biodiesel and its fuel efficiency. Saturated FAMEs are likely to be more reactive upon exposure to oxygen in the air [26]. The oxidized products can cause various problems in diesel engines such as corrosion of metals, fuel filter plugging, injector fouling, and others [27]. As discussed in Table 4, the fraction of saturated FAMEs in BSFL-derived biodiesel was higher than that of other biodiesels. The high quantity of saturated FAMEs is indeed desirable to have higher tolerance against oxidation reactions with air. However, the oxidation stability of BSFL-derived biodiesel was $0.8 \mathrm{~h}$. Although the fuel itself did not meet the quality standards of Korea and EU, the oxidation stability was significantly improved to $7.7 \mathrm{~h}$ in the addition of a practically used antioxidant, $200 \mathrm{mg}$ of tert-butylhydroquinone in $1 \mathrm{~kg}$ of biodiesel. Nevertheless, the further investigation to determine the factors, leading to low oxidation stability of BSFL-derived biodiesel, would be important future study. The oxidation stability can be also susceptible to heat, and other impurities presented in the fuel.

One of the major concerns when using biodiesel in internal combustion engine is its low temperature operation ability. To measure the cold flow properties, cloud point (CP), pour point (PP), and cold filter plugging point (CFPP) are examined. The CP is the temperature at which a liquid component within biodiesel precipitates on cooling test, and PP refers to the lowest temperature that a fuel can migrate when the container is tipped. CFPP for biodiesel is the highest temperature when a given amount of it fails to pass through a filter. Among them, Korea biodiesel standard has a quality criterion of CFPP $\left(0^{\circ} \mathrm{C}\right)$, and the BSFL-derived biodiesel met the CFPP criterion. Comparing to other cold flow properties of BSFL biodiesel with other biodiesels, it had the second best cold flow properties in reference to five representative biodiesels (Table 6).

\section{Conclusions}

Biodiesel was synthesized from black soldier fly larvae (BSFL) grown on food waste. Various fuel properties of the biodiesel were examined. The maximum biodiesel yield was $86.51 \%$ at $70^{\circ} \mathrm{C}$ for $6 \mathrm{hr}$ when lipid to methanol ratio was 1:8 with $5 \% \mathrm{H}_{2} \mathrm{SO}_{4}$ catalyst. High acid value and sulfur contents in the biodiesel were significantly reduced through decompression distillation. The properties of the biodiesel met the Korea standard except oxidation stability, but the oxidation stability was improved in the addition of an antioxidant. These proved the feasibility of BSFL biodiesel to be used as a transportation fuel. 


\section{Acknowledgments}

This work was supported by the Korea Institute of Planning and Evaluation for Technology in Food, Agriculture, Forestry and Forestry(IPET) through Useful Agricultural Life Resources Industry Technology Development Program, funded by Ministry of Agriculture, Food and Rural Affairs(MAFRA)(321096-2).

\section{Author Contributions}

J.-Y.P. (Research scientist) conceptualized, conducted formal analysis, and wrote original manuscript. S.J. (Postdoctoral researcher) conducted formal analysis and data interpretations, visualized, and wrote original manuscript. Y.-G.N. (Research scientist) conducted experiments, reviewed and edited manuscript. C.-H.J. (Senior research scientist) conducted experiments, reviewed and edited manuscript. H.-Y.C. (Researcher) conducted data interpretations, reviewed and edited manuscript. E.-Y.Y. (Professor) conducted data interpretations, reviewed and edited manuscript. S.-h.L. (Company president) conducted data interpretations, reviewed and edited manuscript. E.E.K. (Professor) conceptualized, conducted formal analysis, reviewed and edited manuscript. J.-K.K. (Principal research scientist) conceptualized, conducted formal analysis, reviewed and edited manuscript.

\section{References}

1. Tsang YF, Kumar V, Samadar P, et al. Production of bioplastic through food waste valorization. Environ. Int. 2019;127:625-644.

2. Salomone R, Saija G, Mondello G, Giannetto A, Fasulo S, Savastano D. Environmental impact of food waste bioconversion by insects: Application of Life Cycle Assessment to process using Hermetia illucens. J. Clean. Prod. 2017;140:890-905.

3. Uçkun Kiran E, Trzcinski AP, Ng WJ, Liu Y. Bioconversion of food waste to energy: A review. Fuel 2014;134:389-399.

4. Sudharmaidevi CR, Thampatti KCM, Saifudeen N. Rapid production of organic fertilizer from degradable waste by thermochemical processing. Int. J. Rrecycl. Org. Waste Agric. 2017;6(1): $1-11$.

5. Palmiotto M, Fattore E, Paiano V, Celeste G, Colombo A, Davoli E. Influence of a municipal solid waste landfill in the surrounding environment: Toxicological risk and odor nuisance effects. Environ. Int. 2014;68:16-24.

6. De Baere L. Will anaerobic digestion of solid waste survive in the future? Water Sci. Technol. 2006;53(8):187-194.

7. Van der Horst DJ, Vroemen SF, Van Marrewijk WJA. Metabolism of stored reserves in insect fat body: Hormonal signal transduction implicated in glycogen mobilization and biosynthesis of the lipophorin system. Comp. Biochem. Physiol. B. 1997; 117(4):463-474.

8. Huis Av. Potential of insects as food and feed in assuring food security. Annu. Rev. Entomol. 2013;58(1):563-583.

9. Arrese EL, Soulages JL. Insect fat body: Energy, metabolism, and regulation. Annu. Rev. Entomol. 2010;55(1):207-225.
10. Hoekman SK, Broch A, Robbins C, Ceniceros E, Natarajan M. Review of biodiesel composition, properties, and specifications. Renew. Sust. Energ. Rev. 2012;16(1):143-169.

11. Wang Y-S, Shelomi M. Review of black soldier fly (Hermetia illucens) as animal feed and human food. Foods 2017;6(10):91.

12. Čičková H, Newton GL, Lacy RC, Kozánek M. The use of fly larvae for organic waste treatment. Waste Management. 2015;35:68-80.

13. St-Hilaire S, Sheppard C, Tomberlin JK, et al. Fly prepupae as a feedstuff for rainbow trout, oncorhynchus mykiss. J. World Aquac Soc. 2007;38(1):59-67.

14. Zi-zhe C, De-po Y, Sheng-qing W, et al. Conversion of poultry manure to biodiesel, a practical method of producing fatty acid methyl esters via housefly (Musca domestica L.) larval lipid. Fuel 2017;210:463-471.

15. Ishak S, Kamari A, Yusoff SNM, Halim ALA. Optimisation of biodiesel production of Black Soldier Fly larvae rearing on restaurant kitchen waste. In: Conference Optimisation of biodiesel production of Black Soldier Fly larvae rearing on restaurant kitchen waste; 7-8 May 2018; Yogyakarta, Indonesia. p. 012052.

16. Li Q, Zheng L, Cai H, Garza E, Yu Z, Zhou S. From organic waste to biodiesel: Black soldier fly, Hermetia illucens, makes it feasible. Fuel 2011;90(4):1545-1548.

17. Li Q, Zheng L, Qiu N, Cai H, Tomberlin JK, Yu Z. Bioconversion of dairy manure by black soldier fly (Diptera: Stratiomyidae) for biodiesel and sugar production. Waste Manage. 2011;31(6): 1316-1320.

18. Nguyen HC, Liang S-H, Li S-Y, et al. Direct transesterification of black soldier fly larvae (Hermetia illucens) for biodiesel production. J. Taiwan Inst. Chem. Eng. 2018;85:165-169.

19. Zheng L, Li Q, Zhang J, Yu Z. Double the biodiesel yield: Rearing black soldier fly larvae, Hermetia illucens, on solid residual fraction of restaurant waste after grease extraction for biodiesel production. Renew. Energy. 2012;41:75-79.

20. Zheng L, Hou Y, Li W, Yang S, Li Q, Yu Z. Biodiesel production from rice straw and restaurant waste employing black soldier fly assisted by microbes. Energy 2012;47(1):225-229.

21. Kjeldahl J. Neue Methode zur Bestimmung des Stickstoffs in organischen Körpern. Zeitschrift für analytische Chemie. 1883;22(1):366-382.

22. Michałowski T, Asuero AG, Wybraniec S. The titration in the kjeldahl method of nitrogen determination: base or acid as titrant? J. Chem. Educ. 2013;90(2):191-197.

23. Jung S, Kim H, Fai Tsang Y, Andrew Lin K-Y, Park Y-K, Kwon EE. A new biorefinery platform for producing $\left(\mathrm{C}_{2-5}\right)$ bioalcohols through the biological/chemical hybridization process. Bioresour. Technol. 2020:123568.

24. Karmakar A, Karmakar S, Mukherjee S. Properties of various plants and animals feedstocks for biodiesel production. Bioresour. Technol. 2010;101(19):7201-7210.

25. Ambat I, Srivastava V, Sillanpää M. Recent advancement in biodiesel production methodologies using various feedstock: A review. Renew. Sust. Energ. Rev. 2018;90:356-369.

26. Yamane K, Kawasaki K, Sone K, Hara T, Prakoso T. Oxidation stability of biodiesel and its effects on diesel combustion and emission characteristics. Int. J. Engine Res. 2007;8(3):307-319. 
27. Monirul IM, Masjuki HH, Kalam MA, et al. A comprehensive review on biodiesel cold flow properties and oxidation stability along with their improvement processes. RSC Advances. 2015;5(105):86631-55.
28. Kim JK, Yim ES, Jeon CH, Jung CS, Han BH. Cold performance of various biodiesel fuel blends at low temperature. Int. J. Automot. Technol. 2012;13(2):293-300. 